\title{
Electrorheological Properties of Phosphoric Ester Cellulose Electrorheological Suspensions at Elevated Temperatures
}

\author{
Byeng-Gil AHN, Ung-Soo CHOI, and Oh-Kwan KwON \\ Tribology Research Center, Korea Institute of Science and Technology, \\ P. O. BOX 131, Cheongryang, Seoul 130-650, Korea
}

(Received August 11, 1999)

\begin{abstract}
The electrorheological (ER) behavior of suspensions in silicone oil of phosphoric ester cellulose powder (average particle size: $17.77 \mu \mathrm{m}$ was investigated at elevated temperatures up to $100^{\circ} \mathrm{C}$. For development of anhydrous ER suspensions for use at wide temperature range, the effect of temperature on ER activity has studied. Anhydrous ER suspensions were mixed with the phosphoric ester cellulose particles made from the phosphoric ester reactions of cellulose. During increasing temperature, not only analysis of electrical properties, such as dielectric constant, current density and electrical conductivity but also rheological properties of ER suspensions were studied. Current density, conductivity and electrorheological effect $\left(\tau_{\mathrm{A}} / \tau_{0}\right)$ of phosphoric ester cellulose ER suspensions showed law dependence on temperature. Shear stress was closely related to the square of dielectric constant mismatch parameter $\left(\beta^{2}\right)$ under constant shear rate and electric field.
\end{abstract}

KEY WORDS Phosphoric Ester Reactions of Cellulose / Dielectric Constant Mismatch Parameter/ Anhydrous Electrorheological Suspension / Electrorheological Effect /

Fluids which take on the characteristics of solids upon application of an electric field are known as electrorheological (ER) suspensions. Dramatic rheological effects are reversible and in most fluids quite fast $(\cong 1 \mathrm{~ms})$. They were first discovered by Winslow in the early 1940 's and the phenomenon sometimes bears his name, Winslow effect. ${ }^{1}$ These suspensions generally consist of micron or submicron particles dispersed in a dielectric liquid. A key to their response lies in the fact that particles strongly polarize in presence of an electric field. Dielectric mismatch between particles and carrier fluid gives rise to observed effects. ${ }^{2}$

Early developed ER suspensions are mostly wet systems, where water plays a specific role in the ER effect. There are a number of theories to explain the function of water. In most theories, water increases the interfacial polarization of the particles by allowing or enhancing ionic migration and the formation of polarizable double layer. Both theory and practice indicate that moist ER suspensions are essentially limited to a narrow temperature range and show undesirable levels of conductivity arising from mobile ions. ${ }^{3}$

Since then research on ER suspensions has been done both theoretically and experimentally. One significant development in electrorheology is the discovery of an anhydrous (dry-base) ER suspension using semiconducting polymer like polyaniline ${ }^{4}$ poly(acene quinone) radicals. ${ }^{5}$ One-phase ER suspension using liquid crystalline polymer was also reported ${ }^{6}$ and suggests the possibility of resolving problems caused by presence of solid particles such as sedimentation of solid particles.

The present work examines the electrorheological properties of anhydrous ER suspensions of phosphoric ester cellulose particles ${ }^{7}$ at increasing temperatures up to $100^{\circ} \mathrm{C}$ by studing temperature dependence of ER suspension's electrical and rheological properties. Shear stress-shear rate behavior of phosphoric ester cellulose ER suspensions was measured with increase temperature by a Physica rheolometer (MC100) connected to a high-voltage generator (HVG 500).

\section{EXPERIMENTAL}

\section{Design of Anhydrous ER Suspensions}

Synthesis of Phosphoric Ester Cellulose Particles. Aqueous solutions at $2.5 \mathrm{~mol}$ of phosphoric acid ( $85 \%$ orthophosphoric acid) containing $4 \mathrm{~mol}$ of urea were stirred for half an hour at room temperature for uniformity of solution, and ammonium phosphate was generated by reaction of phosphoric acid and urea. Raw cellulose particles (Sigmacell, Sigma Chemical Co., average particle size $20 \mu \mathrm{m}$ ) were introduced into the ammonium phosphate solution and maintained at $20^{\circ} \mathrm{C}$ for $24 \mathrm{~h}$.

After $24 \mathrm{~h}$, cellulose particles were separated from ammonium phosphate solution by filtering and placed in an electrical furnace for phosphoric ester reactions ${ }^{7}$ of cellulose particles. After maintaining $2 \mathrm{~h}$ at $80^{\circ} \mathrm{C}$, furnace temperature was increased to $150^{\circ} \mathrm{C}$ and maintained for $2 \mathrm{~h}$. The phosphoric ester cellulose particles made from phosphoric ester reactions of cellulose were neutralized by $5-6$ washings with distilled water.

Phosphoric ester cellulose particles was controlled by a sieve shaker (passing $26 \mu \mathrm{m}$ ). To remove moisture from the particles, they were dried in vacuum oven at $100^{\circ} \mathrm{C}$ for $48 \mathrm{~h}$. Particle size distribution was measured by Image Analyzer System (Model Omnimet 2, UK), and mean particle size was $17.77 \mu \mathrm{m}$.

Preparation of Phosphoric Ester Cellulose ER Suspensions. Dried phosphoric ester cellulose particles were mixed with anhydrous silicone oil $(50 \mathrm{cS}$, Shin-Etsu Silicone Co., Japan), prepared by exposing the oil to molecular sieves for one week. ER suspensions were made by mixing $20 \mathrm{vol} \%$ of phosphoric ester cellulose particles and 80 vol\% of silicone oil with ball-mill for $24 \mathrm{~h}$ for uniform dispersion. 


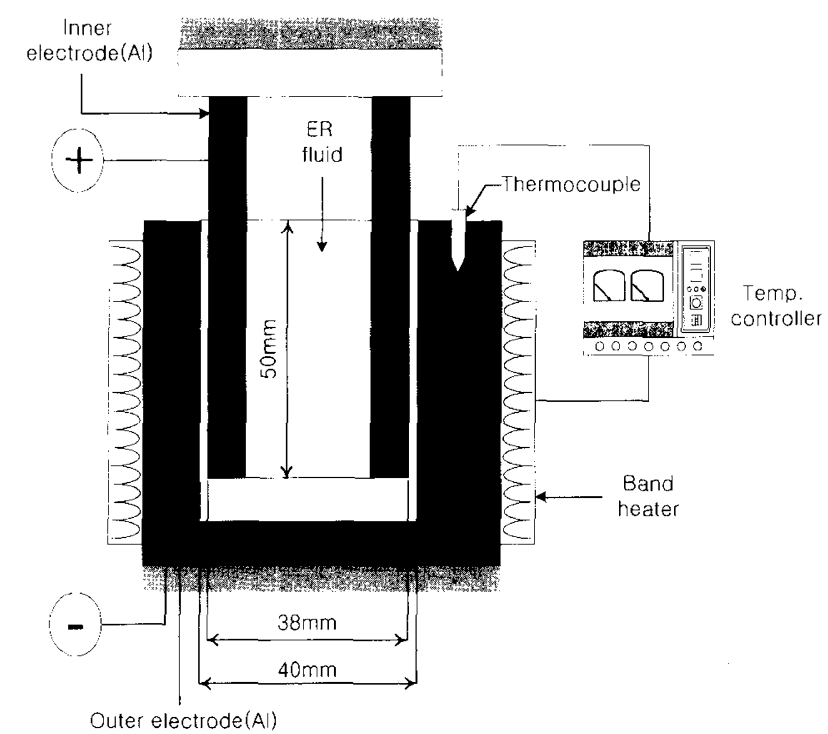

Figure 1. Schematic diagram of electrode for measuring current density and electrical conductivity of ER suspensions at elevated temperature.

\section{Characterization of ER Suspensions Based on Tempera- ture}

Electrical Measurement at Elevated Temperature.

Dielectric and conductive properties of phosphoric ester cellulose ER suspensions were measured with variation in temperature. Arrangement of dispersed particles (i.e., chain formation) influences the electrical properties of these fluids (Miller and Jones, 1988), ${ }^{8}$ and thus the following method was used to determine dielectric properties of ER suspensions. Experiment was performed with increasing temperature with a DC bias LCR meter (Hewlett Packard, HP 4263B, U.S.A). Dielectric constants were calculated by capacitance ${ }^{9}$ of ER suspensions. An LCR meter was used with high voltage bias. The equation used was as follows,

$$
K_{\mathrm{s}}=\left[C_{\text {measure }}-C_{\text {air }}\right] /\left[C_{\text {theory }}+1\right]
$$

where $K_{\mathrm{s}}$ is dielectric constant of ER suspensions, $C_{\text {measure }}$ measuring capacitance of $\mathrm{ER}$ suspensions, $C_{\text {air }}$ capacitance of air, and $C_{\text {theory }}$ theoretical capacitance of free space which can calculate as,

$$
C_{\text {theory }}=2 \pi \varepsilon_{0} L / \ln \left(r_{2} / r_{1}\right)
$$

where $K_{\mathrm{s}}$ is the dielectric constant of free space, $L$ cylinder gap between bob and cup, and $r_{2}, r_{1}$ inner radius of cup and outer radius of bob, respectively. DC conductivity determined by measuring the current on the high electric field conditions. Fluid specimens were held in a heating aluminum cup as seen in Figure 1, whose outer diameter, inner diameter and height were $40 \mathrm{~mm}, 38$ $\mathrm{mm}$, and $50 \mathrm{~mm}$, respectively, with a flat bottom made by plastic. Electrode area for calculating electrical properties was $59.69 \mathrm{~cm}^{2}$ and thickness, $1 \mathrm{~mm}$. When using other polymer particles, poly ( $p$-phenylene), as ER particles, the particles aggregated to one electrode under DC fields. But the developed ER particles, phosphoric ester cellulose, did not aggregate to one electrode under high DC fields (up to $4.5 \mathrm{kV} \mathrm{mm}^{-1}$ ). Data were collected after

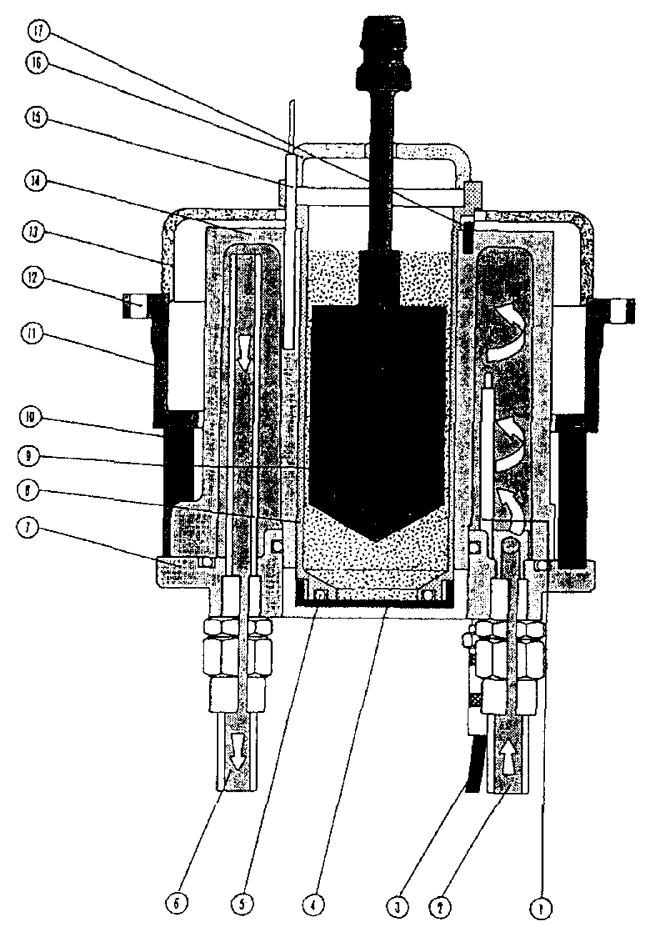

Figure 2. Schematic diagram of viscometer for ER fluids. 1: thermocouple, 2: thermal liquid-inlet, 3: cable of thermocouple, 4: bottom of measuring cup, 5: packing ring, 6: thermal liquid-outlet, 7: cover, 8: measuring cup, 9: measuring bob, 10: insulating distance pins, 11: holding flange, 12: bore for fixing screw M5, 13: plastic cover, 14: thermal liquid circulation chamber, 15: temperature probe of thermocouple, 16: plastic cover, 17: positioning pin for measuring cup.

ER fluid was initially stirred at $E=0$, and increased up to $4.5 \mathrm{kV} \mathrm{mm}^{-1}$.

The equation of current density $\left(j_{\mathrm{f}}\right)$ is

$$
j_{\mathrm{f}}=\frac{I_{\mathbf{f}}}{A}
$$

The conductivity $\left(\sigma_{f}\right)$ of ER fluids was calculated as,

$$
\sigma_{\mathrm{f}}=\frac{\Delta j_{\mathrm{f}}}{\Delta E}
$$

where $A$ is electrode area in contact with ER suspension, If current under constant electric field, $E$ electric field and $\Delta j_{\mathrm{f}}$ the difference of current density of ER suspension as the difference in electric fields $(\Delta E)$.

Dielectric constant of ER suspension calculated by linear equation of volume fraction ${ }^{8}$ of dispersed particles is as follows,

$$
K_{\mathrm{s}}=K_{\mathrm{p}} \phi+K_{\mathrm{f}}(1-\phi)
$$

where $K_{\mathrm{p}}$ and $K_{\mathrm{f}}$ are the dielectric constant of dispersed particle and insulating oil, respectively, $\phi$ the volume fraction of dispersed particle and $K_{s}$ the dielectric constant of ER suspension.

Rheological behavior of ER suspensions with increasing temperature were determined using Physica rheolometer (MC100) as seen in Figure 2, a coaxial arranged design for relatively low strain and strain rate used by a conventional mechanical test machine. High-voltage 


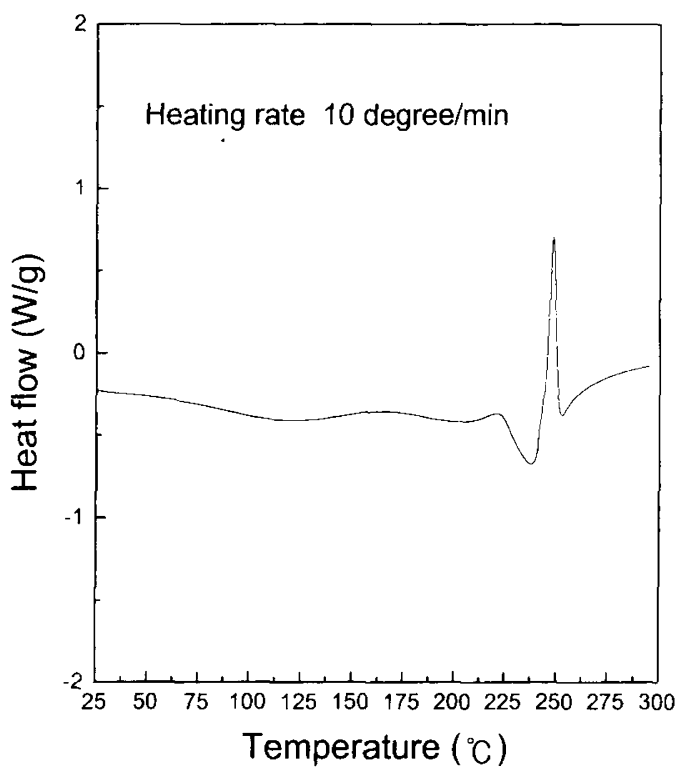

Figure 3. DSC curve of phosphoric ester cellulose particles treated with $2.5 \mathrm{~mol}$ of phosphoric acid and $4 \mathrm{~mol}$ of urea.

generator (HVG500) was supplied and connected to the cup and bob of Couette type rheometer by a thin wire. Data were obtained with increasing temperature up to $100^{\circ} \mathrm{C}$ at constant shear rate $\left(100 \mathrm{~s}^{-1}\right)$ and electric field.

For ER suspensions, the electrorheological effect (ER effect, $\eta_{\mathrm{R}}$ or $\tau_{\mathrm{R}}, \eta_{\mathrm{R}}=\eta_{\mathrm{A}} / \eta_{0}$ or $\left.\tau_{\mathrm{R}}=\tau_{\mathrm{A}} / \tau_{0}\right)$ at elevated temperatures is very important for application to real mechanical parts, where $\eta_{\mathrm{A}}$ (or $\tau_{\mathrm{A}}$ ) and $\eta_{0}$ (or $\tau_{0}$ ) stand for the apparent viscosity (or shear stress) with and without an electric field under constant temperature, respectively.

\section{RESULTS AND DISCUSSION}

\section{Analysis of Phosphoric Ester Cellulose Particles}

Density measurement of phosphoric ester cellulose particles was done by a Pycnometer. Density was $1.28 \pm$ $0.05 \mathrm{~g} \mathrm{~cm}^{-3}$. Particle size of phosphoric ester cellulose particles was controlled by sieve shaker (passing $26 \mu \mathrm{m}$ sieve). To remove moisture from the particles, they were dried in the vacuum oven at $100^{\circ} \mathrm{C}$ for $48 \mathrm{~h}$. Particle size distribution measured by Image Analyzer System (Model Omnimet 2, UK) and their mean particle size was $17.77 \mu \mathrm{m} .{ }^{7}$ Thermal stability of phosphoric ester cellulose particles was examined from DSC curve up to 200 ${ }^{\circ} \mathrm{C}$, as shown in Figure 3. In case of phosphoric ester cellulose particles, no chemical reaction or decreasing weight was found below $200^{\circ} \mathrm{C}$. Decomposition temperature of cellulose is between $200^{\circ} \mathrm{C}$ and $270^{\circ} \mathrm{C} .{ }^{10}$ The phosphoric ester cellulose particles dispersed into silicone oil were thus stable below $200^{\circ} \mathrm{C}$, proving that the ER suspensions based on phosphoric ester cellulose are anhydrous ER suspensions.

\section{Electrical Properties at Elevated Temperature}

The continuous phase of a ER suspension is typically a nonconductive and low dielectric constant oil. The current density and conductivity of phosphoric ester cellulose ER fluids, as shown in Figures $4 \mathrm{a}$ and $4 \mathrm{~b}$, were
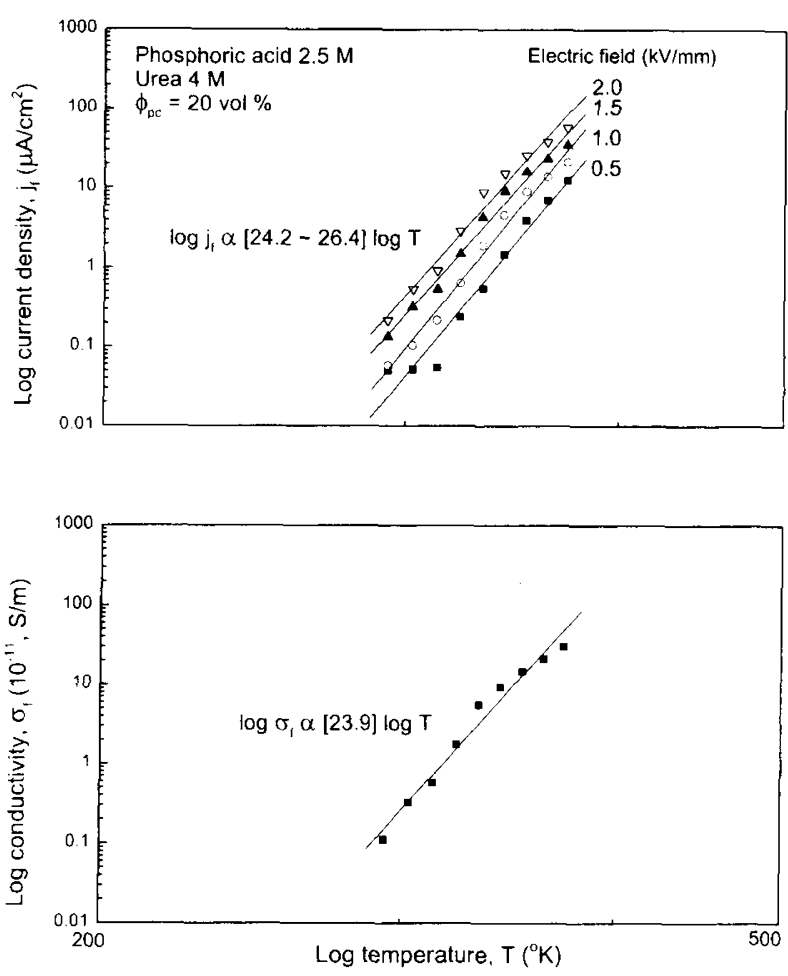

Figure 4. Current density and conductivity of phosphoric ester cellulose ER suspensions plotted against temperature.

measured at elevated temperatures. Volume fraction of phosphoric ester cellulose particles was maintained constant, but current density and conductivity should be measured differently. Current density $\left(j_{\mathrm{f}} \propto T^{m}, m=24.2\right.$ -26.4) and conductivity $\left(\sigma_{\mathrm{f}} \propto T^{n}, n=23.9\right)$ increased with temperature, and were proportional to temperature with power law under constant concentration.

The dielectric behavior of $50 \mathrm{cS}$ silicone oil with variation temperature up to $100^{\circ} \mathrm{C}$ is shown in Figure 5. The dielectric constant of silicone oil decreased with increasing temperatures.

The dielectric behavior of phosphoric ester cellulose ER suspensions (constant volume fraction) with variation temperature up to $100^{\circ} \mathrm{C}$ is shown in Figure 6 at constant volume fraction, the dielectric constant of ER suspensions based on phosphoric ester cellulose particles increased till the temperature arrived at $80^{\circ} \mathrm{C}$. But above $80^{\circ} \mathrm{C}$, it was nearly constant. For anhydrous ER suspensions, shear stress behavior in the electric field is closely related to the dielectric constant of ER suspension. This ER behavior named "point dipole mechanism" was proposed by Klingenberg and Zukoski $(1990)^{11}$ and Conrad et al. (1991). ${ }^{8}$ Assuming two dipoles separated more than their radii (a) in suspension, point dipole force $\left(F_{d}\right)$ between two particles may be written as follows,

$$
F_{\mathrm{d}}=6 p^{2} / 4 \pi \varepsilon_{0} K_{\mathrm{f}} R^{4}
$$

where $p$ is the dipole moment of dispersed particles, $\varepsilon_{0}$ the dielectric constant of free space, and $R$ the distance between two particles. The point dipole force $\left(F_{d}\right)$ between two particles is as follows, 


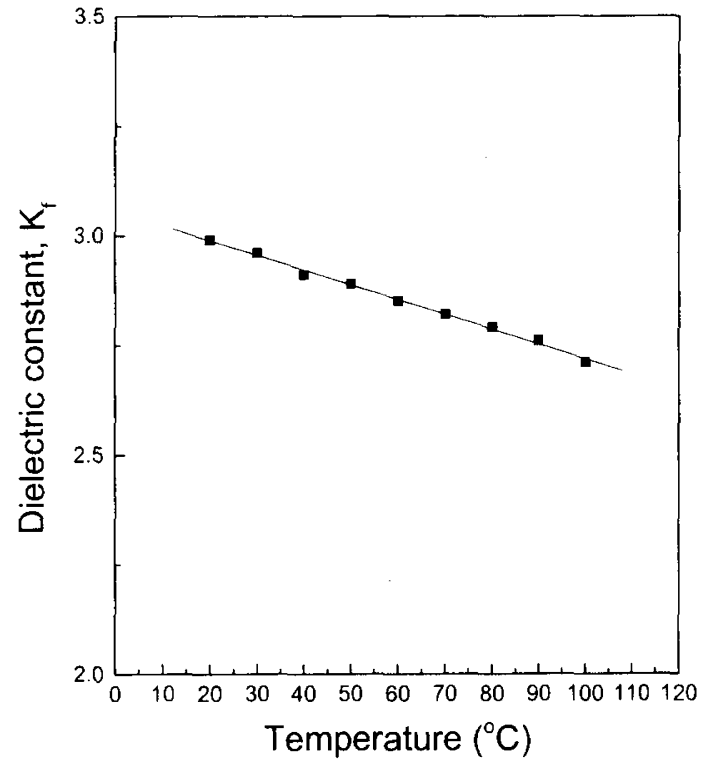

Figure 5. Dielectric constant of the $50 \mathrm{cS}$ silicone oil vs. temperature.

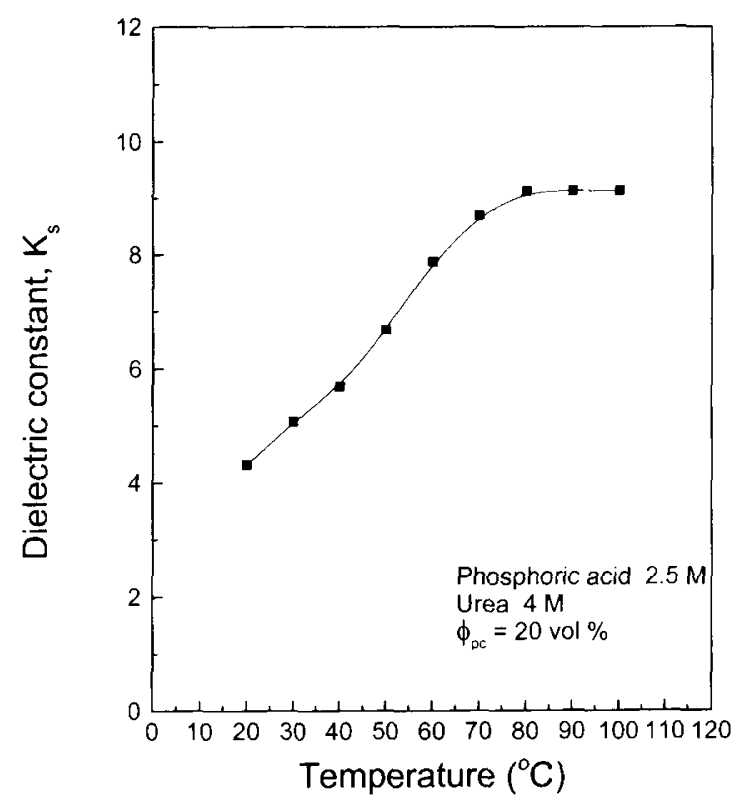

Figure 6. Dielectric constant of phosphoric ester cellulose ER fluids plotted against temperature.

$$
p=4 \pi \varepsilon_{0} K_{\mathrm{f}} a^{3} E\left(\frac{K_{\mathrm{p}}-K_{\mathrm{f}}}{K_{\mathrm{p}}+2 K_{\mathrm{f}}}\right)
$$

where $a$ is the radius of dispersed particle and $E$ the electric field. Therefore the point dipole force $\left(F_{\mathrm{d}}\right)$ between two particles is as follows,

$$
F_{\mathrm{d}}=24 \pi \varepsilon_{0} K_{\mathrm{f}} a^{6} \beta^{2} E^{2}
$$

Where $\beta$ is the dielectric constant mismatch parameter of ER suspensions which is shown as $\left\{\left(K_{\mathrm{p}}-K_{\mathrm{f}}\right) /\left(K_{\mathrm{p}}+\right.\right.$ $\left.2 K_{\mathrm{f}}\right)$.

From equation 8 , the point dipole force $\left(F_{\mathrm{d}}\right)$ between two particles under constant $E, a$ and $K_{\mathrm{f}}$ can be shown as follows,

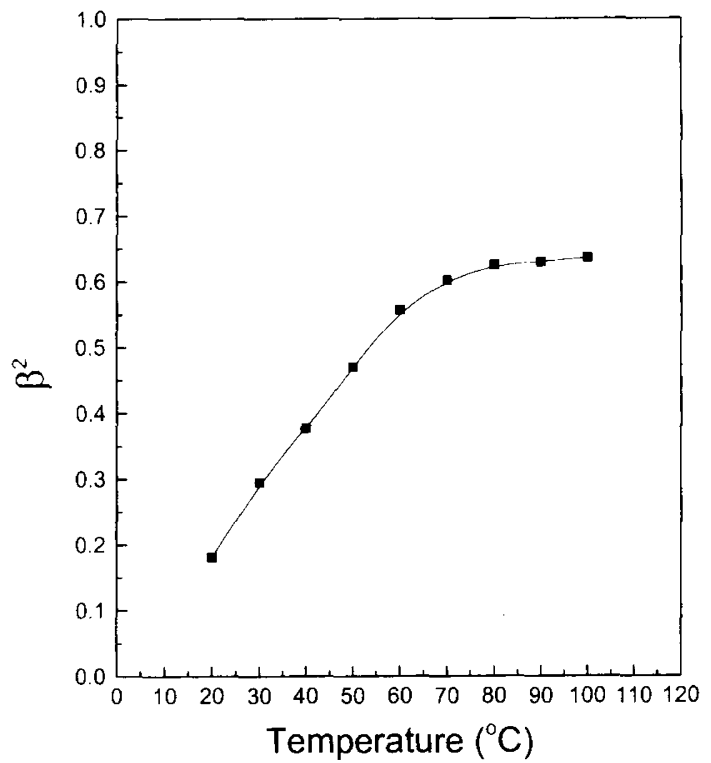

Figure 7. Square of the dielectric mismatch parameter, $\beta=\left(K_{\mathrm{p}}\right.$ $\left.-K_{\mathrm{f}}\right) /\left(K_{\mathrm{p}}+2 K_{\mathrm{f}}\right), v s$. temperature.

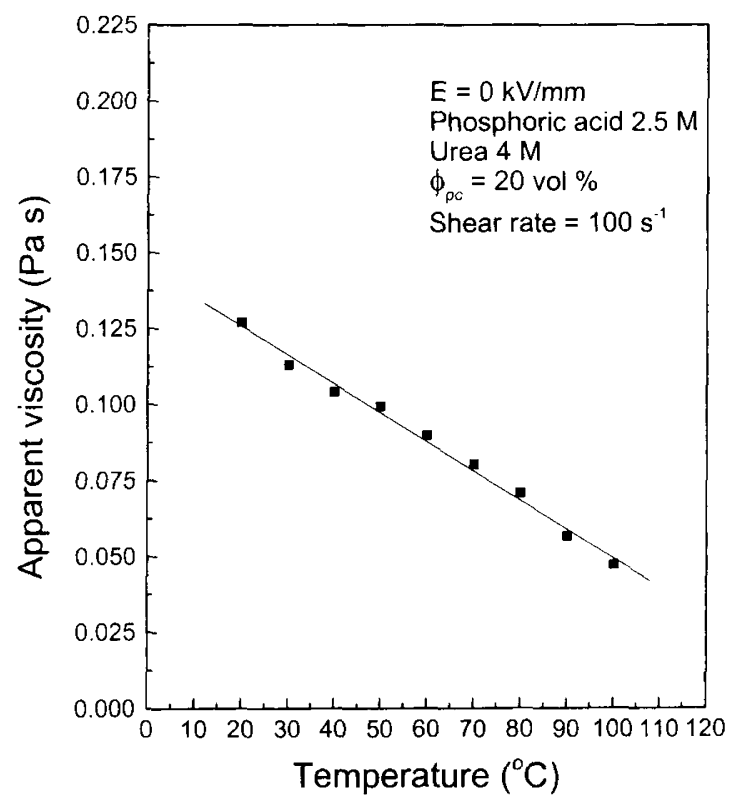

Figure 8. Apparent viscosity behavior of phosphoric ester cellulose ER fluids plotted against temperature.

$$
F_{\mathrm{d}} \propto \beta^{2}
$$

From Figures 5, 6, and equation 4, variation of $\beta^{2}$ at elevated temperature can be calculated and the results are shown in Figure 7. $\beta^{2}$ increased until temperature up to $80^{\circ} \mathrm{C}$. But, as temperature passed over $80^{\circ} \mathrm{C}$, it remained nearly constant. From Figure 7, it is possible to guess that shear stress of anhydrous ER suspensions developed in this study has the highest point at $80^{\circ} \mathrm{C}$ at constant shear rate and electric field.

Rheological Measurement at Elevated Temperature. Viscosity $\left(\eta_{0}\right)$ without electric field has large influence on the electrorheological effect of anhydrous ER suspensions of phosphoric ester cellulose particles and was measured at temperatures up to $80^{\circ} \mathrm{C}$ as seen Figure 8 . 


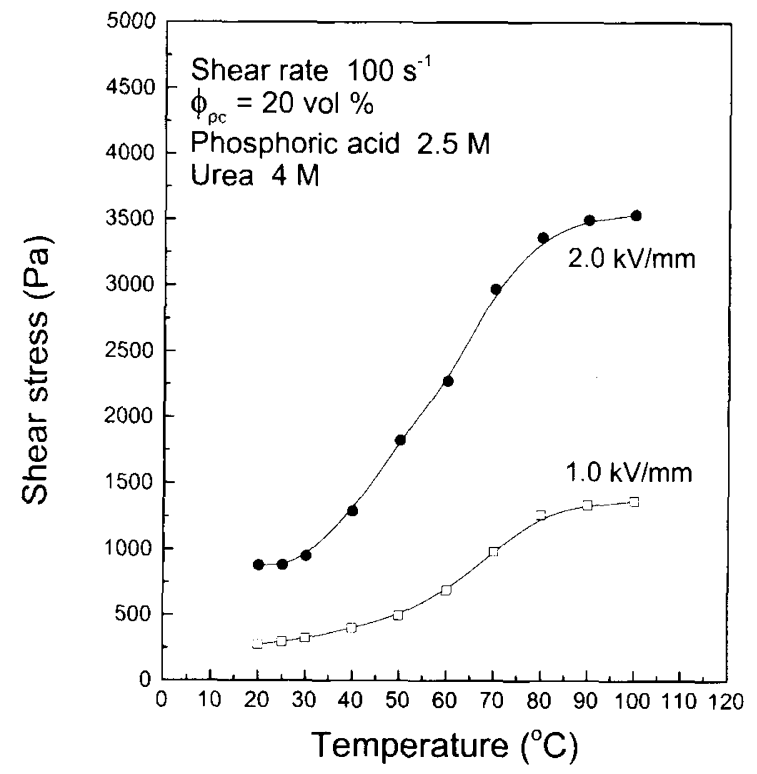

Figure 9. Shear stress $v s$. temperature for $E=1 \mathrm{kV} \mathrm{mm}^{-1}$ and 2 $\mathrm{kV} \mathrm{mm}^{-1}$.

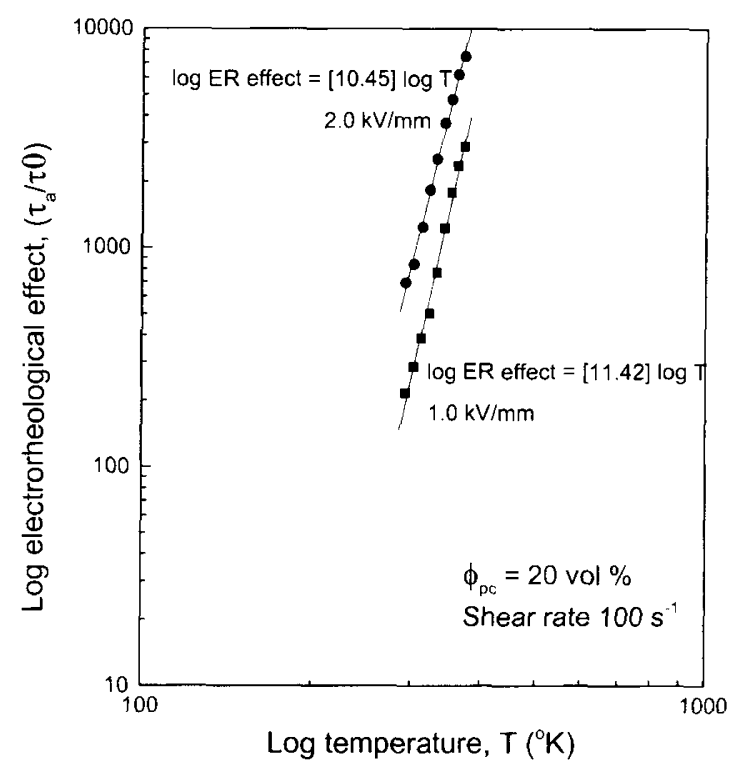

Figure 10. Electrorheological effect of phosphoric ester cellulose ER fluids plotted against temperature.

Viscosity of developed ER suspensions was noted to be that of Newtonian fluids under without DC fields. From the results of Figure 8, the apparent viscosity $\left(\eta_{0}\right)$ measured without electric fields decreased with temperature.

When strain rate $\left(100 \mathrm{~s}^{-1}\right)$ and electric field (1 $\mathrm{kV} \mathrm{mm} m^{-1}$ and $2 \mathrm{kV} \mathrm{mm}^{-1}$ ) were constant, shear stress behavior was measured up to $80^{\circ} \mathrm{C}$ as seen in Figure 9. Shear stress increased with temperature under constant shear rate and electric field. But, as soon as ER suspension temperature is over $80^{\circ} \mathrm{C}$, increasing shear stress with temperature is abruptly stopped. These results can be explained from Figure 7. Till $80^{\circ} \mathrm{C}$, shear stress of ER suspension was increased due to increasing value of $\beta^{2}$. Slowdown of shear stress was observed over $80^{\circ} \mathrm{C}$ temperature because the increase in $\beta^{2}$ disappears. This behavior can be deduced from eq 7 .

Under constant shear rate $\left(100 \mathrm{~s}^{-1}\right)$, electrorheological effect $\left(\tau_{\mathrm{A}} / \tau_{0}\right)$ of anhydrous ER suspensions of phosphoric ester cellulose particles was measured at different temperatures as seen in Figure 10. Electrorheological effects increased with power law on increasing temperature. This proves that ER fluid developed in this study is anhydrous ER suspension which show good ER activity at over $80^{\circ} \mathrm{C}$.

\section{CONCLUSIONS}

Phosphoric ester cellulose particles dispersed into silicone oil were stable below $200^{\circ} \mathrm{C}$, proving that ER suspensions are anhydrous ER suspensions. Current density $\left(j_{\mathrm{f}} \propto T^{m}, m=24.2-26.4\right)$ and conductivity $\left(\sigma_{\mathrm{f}} \propto T^{n}\right.$, $n=23.9$ ) of phosphoric ester cellulose ER suspension increased with increasing temperature, and had a power law dependence on temperature under constant concentration. The square of dielectric constant mismatch parameter $\left(\beta^{2}\right)$ at elevated temperatures was closely related to shear stress of ER suspensions. The electrorheological effect of phosphoric ester cellulose ER suspensions increased with power law on increasing temperature, proving that ER suspension developed in this study was an anhydrous ER suspension which can be used at wide temperature range.

\section{REFERENCES}

1. W. M. Winslow, J. of Physics, 20, 1137 (1949).

2. T. B. Jones, Proceedings of Second International Conference on ER fluid, 14 (1990).

3. Yu. F. Deinega and G. V. Vinogradov, Rheo. Acta, 23, 636 (1984).

4. C. J. Gow and C. F. Zukoski, J. Colloid and Interface Sci., 136, 175 (1990).

5. H. Block and J. P. Kelly, U. S. Patent 4687589, 1987.

6. I. K. Yang and A. D. Shine, J. Rheol., 36, 1079 (1992).

7. B. G. Ahn, U. S. Choi, and O. K. Kwon, Polym. J., 31, 494 (1999).

8. H. Conrad, A. F. Sprecher, Y. Choi, and Y. Chen, J. Rheology, 35, 1393 (1991).

9. C. Wu and H. Conrad, J. Phys. D: Appl., 29, 3147 (1996).

10. J. Brandrup and E. H. Immergut, "Polymer Handbook", Jone Wiley \& Sons, Inc., 3rd ed, New York, N.Y., 1989, p V/122.

11. D. J. Klingenberg and C. F. Zukoski, Langmuir, 6, 15 (1990). 